\title{
BUEN PROVECHO: A STORY OF LATINA WOMEN, IMMIGRATION, AND FOOD
}

\author{
by
}

Julia Walters, BA., University of Guelph, 2014

\begin{abstract}
A Major Research Paper
presented to Ryerson University

in partial fulfillment of the requirements for the degree of

\author{
Master of Arts \\ in the program of \\ Immigration and Settlement Studies
}

Toronto, Ontario, Canada, 2016

(C) Julia Walters 2016 


\section{AUTHOR'S DECLARATION FOR ELECTRONIC SUBMISSION OF A MAJOR RESEARCH PAPER}

I hereby declare that I am the sole author of this Major Research Paper. This is a true copy of the MRP, including any required final revisions, as accepted by my examiners.

I authorize Ryerson University to lend this MRP to other institutions or individuals for the purpose of scholarly research.

I further authorize Ryerson University to reproduce this MRP by photocopying or by other means, in total or in part, at the request of other institutions or individuals for the purpose of scholarly research.

I understand that my MRP may be made electronically available to the public. 


\title{
BUEN PROVECHO: A STORY OF LATIN WOMEN, IMMIGRATION, AND FOOD
}

\author{
Julia Walters \\ Master of Arts, 2016 \\ Immigration and Settlement Studies \\ Ryerson University
}

\begin{abstract}
Food is a highly useful tool to better understand the process of immigration and acculturation and it speaks to deeper symbolic meanings of social realities, especially in the lives of immigrants. As such, this paper explores the deeper symbolic meaning behind food purchasing, preparation, and consumption (PPC) habits within the Latin American community who have settled in Toronto and the Greater Toronto Area. Here I argue that food PPC is a highly gendered experience and is reflective of the integration and acculturation process as a whole within the Canadian context. Food cannot be separated from its deeper symbolic meaning and within the field of immigration, food can and ought to be used as a lense of analysis.
\end{abstract}

\section{Key Words:}

Food, women, integration, acculturation, immigration, Canada 


\section{ACKNOWLEDGEMENTS}

Firstly, I would like to thank my 2015-2016 Immigration and Settlement Studies cohort for all their support in both academics and everyday life.

Secondly, I want to thank Mustafa Koç for his wisdom and guidance as well as Carmen Schifellite for the academic support as both my research methods professor and my secondary reader.

I would like to thank my mother and father for always supporting me in whatever path I have chosen to take in life. Whether dropping me off at the airport as I explore the world, rooting me on at sporting events, or reading my papers, their love and support is endless.

Finally, I would also like to dedicate this paper to all those along the way that have contributed to my love and passion for Latin America and Latin Studies. 


\section{TABLE OF CONTENTS}

Authors Declaration of Electronic Submission...........................................II

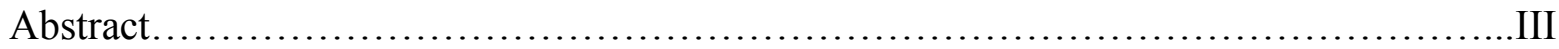

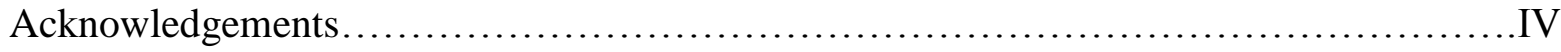

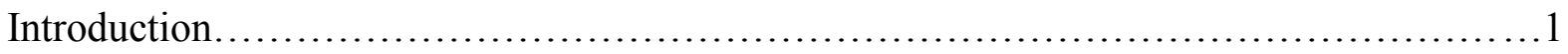

1.0 Literature Review...............................................................

1.1 Theoretical Lenses................................................................. 6

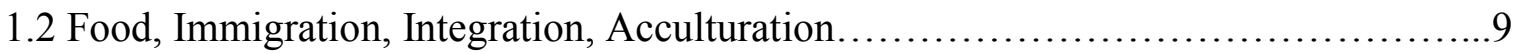

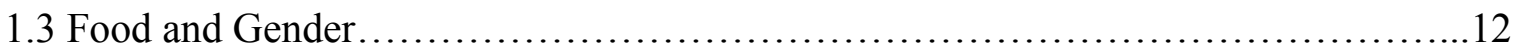

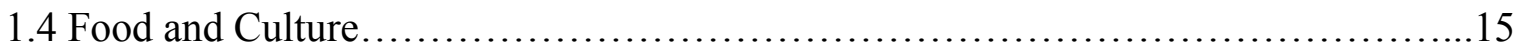

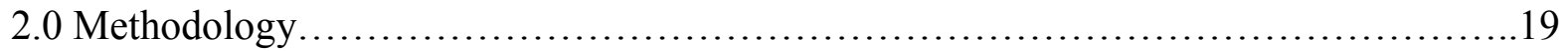

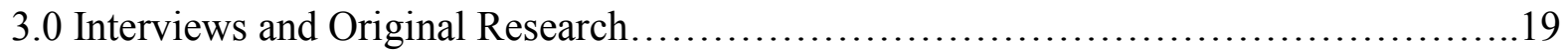

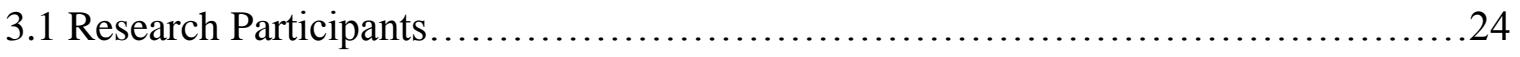

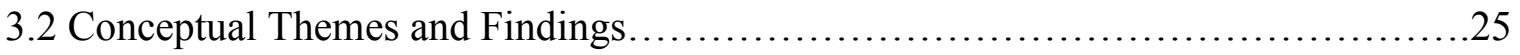

4.0 Conclusion and Closing Remarks............................................... 37

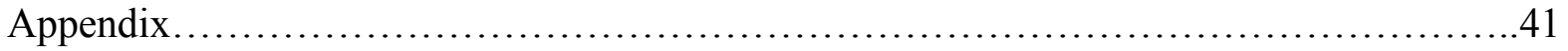

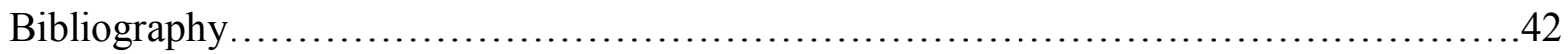




\section{Introduction: Understanding Food as a Social Phenomena}

As the famous 18th Century French Lawyer and politician Jean Anthelme Brillat-Savarin once said, "Tell me what you eat, and I shall tell you what you are" (cited in Welsh and Koç, 2001). This expression has been used time and time again, taking on a much simpler lexical phrase which goes, "you are what you eat". One can safely assume that all readers have heard this phrase in a multitude of situations throughout various stages of their life. With that being said, despite the commonality of the phrase, it is important to think of the different significances and meanings behind this popular statement. Firstly, one could examine this statement from a nutritional perspective to draw connections between an individual's dietary choices and their overall internal health; such that, unhealthy dietary choices result in an unhealthy individual while healthy choices equate to a healthy individual. Secondly, one could examine this statement from a social understanding of food which aims to put a deeper social meaning behind something that could otherwise be written off as trivial. This particular way of understanding food was popularized by Levi-Strauss (1966), "who sought to understand food as a cultural system, a system of symbols, categories, and meanings" (Appadurai, 1981, p.494). To elaborate further, as explained by Sutton (2010), although one can not ignore the essential life sustaining nutritional quality associated with food consumption, food ought to be used as a subject of analysis which is telling of one's social conditions, cultural or religious values, and bridges the boundaries of the public/private and the collective/individual. Simply put, food is an effective way to better understand the social realities of an individual's life. These social realities intersect and speak to the many competing realities of an individual's day to day existence. For instance, imagine a hypothetical university student who, as a staple of their diet, eats Kraft Dinner with canned organic tuna mixed into the macaroni noodles. What do such purchasing, preparation and 
consumptive (PPC) activities tell us about this individual? To start, Kraft Dinner is inexpensive and thus one could make assumptions about this student's economic status. Moreover, organic tuna sheds light on this students ethical or moral compass or personal ideas regarding global/environmental food systems. Or perhaps, this student is an unskilled cook and Kraft Dinner with tuna is an easy option for the culinarily impaired. No matter the reason, or reasons, why this hypothetical student chooses to eat Kraft Dinner and tuna, the idea at hand is that food and food PPC is not a passive experience, but rather, indicates a particular social reality or phenomenon of those interacting with it.

In accordance with this social understanding of "you are what you eat", the primary purpose of this major research paper (MRP) is to use food as a lens to better understand the phenomena of immigration and settlement within the Canadian context. To be sure, this type of research has been conducted before, and as such, my work will be adding to the the already vast and well developed body of literature which looks at the social significance of food within the context of immigration through a gendered lens. For instance, this MRP has called heavily upon research conducted by Vallianatos and Raine (2008). In this publication, Vallianatos and Raine bring to light cultural maintenance through food. Vallianatos and Raine (2008) state that, Through women's gendered roles in providing, preparing and presenting food to their families, they act as gatekeepers as they balance the need to impart family and community values via traditional foods and cuisines, with adjusting to life and foodways in Canada (p.357).

As such, the gatekeepers phenomena which has been explored within the South Asian and Arabic community in Edmonton, Alberta, Canada will be deconstructed and explored within the 
Latin American community. Ultimately, this MRP is not reinventing the wheel, but it is safe to say that I am effectively spinning the wheel in a different direction.

The direction which this MRP has taken is an examination of women (and their families) from Latin America who immigrated to Toronto and the Greater Toronto Area (GTA) and their relationship with food PPC during their immigration process, and in turn, how food can be used to explore topics such as acculturation and integration. In accordance with research conducted by Veronis (2006) the term "Latin American" or "Latino" refers to immigrants from "Spanishspeaking countries in North, Central, and South America; this does not include migrants from the Caribbean or non-Spanish-speaking nations in Latin America" (p.1656). The reason I chose to examine the Latin American community within Toronto and the GTA boiled down to the fact that there is a dearth of literature written about this community within the Canadian context which differs from the United States where there is a high volume of research on Latin American immigrants. This plethora of research within the American context is most likely related to the high number of Latinos living in the United States.

It is no surprise that the U.S is a destination country for immigrants, and even more so, for immigrants from Latin America. The United States proximity to Mexico, Central, and South America, coupled with a mild/warm climate, and perceived economic opportunities, makes the U.S a desirable destination for relocation. Moreover, immigration to the United States is popular, in that, people tend to migrate to where they have family or connections thus meaning the Latino population is increasing steadily within the American context. In fact, as of 2010, "the hispanic population numbered just over 50 million, accounting for one in six Americans" (Norris, 2013, p. 3). On the other hand, although Canada is undeniably an immigration destination country as well, the number of those who immigrate to Canada, or identify as Latino/Hispanic, living in 
Canada, is proportionately and absolutely smaller when compared to our southern neighbour.

Below is a chart created by Doug Norris in his comparison of cultural diversity in the United

States and Canada. This chart is highly effective in looking at the ethnic demographic makeup of these neighbouring, multi-ethnic, immigrant destination countries. I would recommend that the reader focuses their attention on the numbers regarding Latinos/Hispanics in these two countries which I have highlighted.

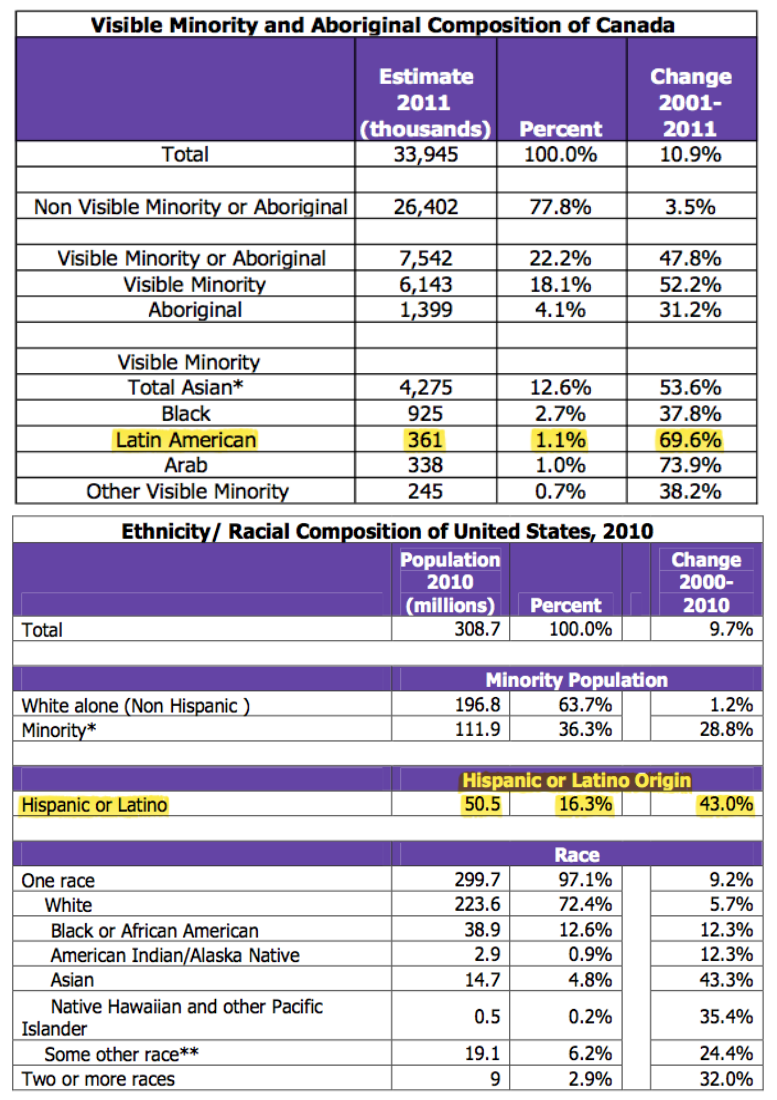

Source: Norris 2013, p 4, 6.

Based on the numbers shown above, one can see that the Latino population in the United States makes up $16.3 \%$ of the total U.S population while Latinos in Canada make up only $1.1 \%$ of the total Canadian population. It is from these numerical population projections that one can make an educated guess as to why there is a dearth of literature on the Latin American community in Canada within settlement literature. As identified by Veronis (2010), Latin 
Americans are a new immigrant group and come from "countries of origin referred to as nontraditional in official immigration discourses" (p.1656). One can assume that as the number of Latino immigrants grows and Latin America becomes a traditional region of origin, literature about the group will increase within the Canadian context. In turn, my MRP can be seen as a stepping stone within immigration, acculturation, and integration literature as it relates to peoples from Latin America, and more specifically, women/mothers from Latin America and their relationship with food PPC. I further outline the specificities of my MRP below.

For this MRP, I used qualitative, interview based methodology to add to the body of literature available on this specific topic. Of the six women from Latin America whom I interviewed, all were mothers. The stories shared (which were specific to food) by the six women are highly telling of their relationship with their home country and culture and their immigration and settlement process within the Canadian context. After conducting extensive research and conducting interviews with six research participants who fit specific inclusion criteria, I conclude that food PPC is an explanatory phenomena which can be used to understand both the migration, acculturation and integration process of Latin Americans within Canadian society as well as the preservation of their home culture within the Canadian context. Simply put, through the semiotic nature of food, I argue that one can better understand the climate of immigration and settlement.

This next section of this paper will help to aid the reader in understanding the literature and concepts available which inspired this particular MRP research project. This next section will contextualize the original research to follow. 


\section{Theoretical Lenses}

\section{Chapter One: Literature Review}

The following section of this paper will be used to explore the literature already available on this topic to give the reader a rich and robust understanding of the topic at hand. Analytical insights from the vast body of food and immigration related literature will be identified and terms such as acculturation and integration will be defined and problematized. The intent of this literature review section is to bridge the works about acculturation, integration, food, and gender, in order to create a strong base for the original research that I conducted in Spring/Summer 2016.

First and foremost, it is necessary before diving into the literature to outline two theoretical frameworks that the reader can engage with and apply across the varied pieces of literature that are referenced within this MRP. Moreover, it is important to note the methodology for compiling and analyzing the sources that are presented within this MRP. All sources were collected, analyzed, and deconstructed with the following lenses in mind.

The first theme which I will present and discuss is marianismo. Perhaps this discourse is not as well known as its opposite, the discourse on machismo; both of which have been developed into analytical frameworks by the structuralist feminist movement (Lloyd, Few \& Allen, 2009). When examining Latin American culture, which encompasses a vast variety of nations and peoples, one can identity a common theme which links these unique and diverse cultures together: machismo. Machismo can be defined as, "a complex ideological system that organizes gender relations and hierarchies, establishing relations of power and domination between men and women" (Parker, 1996, p.62). Within machismo, women typically fall into a position of subordination while men maintain a dominant role. Men control the family's public affairs while, in contrast, a women is responsible for private affairs within the home. Not surprisingly, one of these private affairs is that of taking care of the family which is a defining 
quality of Marianismo. Simply put, marianismo is an anthropological term used to identify social behaviours of Latina women where they act in a self sacrificing manner for the sake of their family (Marano, 2004; Mandez-Luck \& Anthony, 2015). This framework emphasizes the role of socialization in instilling qualities of femininity, submissiveness, and virginity/purity on women while simultaneously demanding them to take responsibility for their families (Mandez-Luck \& Anthony). The qualities of self sacrifice and a "family first" mentality is an interesting and telling angle to examine food PPC habits of Latin American women within the Canadian context or post migration and settlement context in other countries like the United States. According to Mandez-Luck and Anthony (2015), marianismo continues to define caregiving habits, including food PPC, of Mexican women who immigrated to North America and their perceived roles inside the home.

After providing such definitions, I feel it is important to state that I understand such lenses can be essentializing by nature and of course, the relationships between genders as they play out in the public and private sphere take on more intricate nuances (Steven, 1973). Machismo has a tendency to frame men in a negative or villainizing light, while marianismo has a tendency to steal autonomy and victimize women. It is important that readers are conscious of this essentializing nature and identify that the influences of hegemonic discourses are always influenced by real men and women. Theoretical frameworks can create a looming shadow which blocks out the real voices of those being discussed, and therefore, I emphasize that this framework is only useful to a certain degree. Although I am aware of the various critiques of such gendered understandings of Latin America (Ehlers, 1991; Torres, 2002; Seaz, 2009), due to the scope of this paper, I do not intend to add to such critiques, but rather, I am using marianismo (and machismo) to better understand the literature available on Latina women. 
The second theoretical lense which has proven highly useful for my project is gastropolitics (Appadurai, 1981). Gastro-politics (which is highly related to the more popular term of gastronomy), looks at food as "part of a semiotic system in particular social contexts" (Appadurai, 1981, p.495). Gastro-politics uses food to formulate questions about particular societies and social contexts such as, "what do particular actions involving food (and particular foods) "say"? To whom? In what context? To what immediate social consequence? To what structural end?" (Appadurai, 1981, p.495). These questions have been utilized by a variety of scholars and applied to a variety of food related situations to draw meaning to everyday interactions that are often taken for granted (Holzman, 2002; Vallianatos \& Raine, 2008; Trapido, 2011). For instance, under the umbrella of gastro-politics, food has been used to: give insight into the changes of South African society in a post apartheid setting (Trapido, 2011), to examine the ways women use food to influence male "political spheres" in Eastern Africa (Holtzman, 2002), and to explore the dietary trajectory of Gandhi in his transition from masculine meat eater to pious vegetarian, and eventually, his abstinence from food entirely (Mishra, 2002). As such, gastro politics as popularized by Appadurai is a useful tool which can be used in a diverse realm of food related scenarios to extrapolate deeper semiotic meaning.

Some have found this term to be somewhat confusing as it embodies research that seems to span in abstract and unrelated directions as presented in the examples above. For the purpose of my work, the most effective way to understand and grasp the utility of this term is highlighted by Vallianatos and Raine (2008) who argue that gastro-politics is any "social transaction" related to food (p. 361). Perhaps this definition seems broad, but the usefulness of this explanation is that gastro-politics acts as a reminder that food is always a social phenomena. Food cannot be separated from its larger social significance and therefore food always tells us a story. 
Both marianismo and gastro-politics are powerful lenses and set a theoretical base for understanding and deconstructing the sources to come. By using these two theoretical lenses in a complementary manner within my literature review, I intend to highlight the intersectionality of the two.

\section{Setting the Stage for Original Research}

\section{Cultural maintenance within the immigration process: using food to understand acculturation and integration.}

Terms like integration and acculturation can sometimes be used without clearly defining or understanding their specific meanings. To avoid unclear use of such pivotal terms, I will define what these terms mean and their intended application for the purposes of this MRP.

Firstly, acculturation can be defined as "the process of adjusting to a new culture, [and] describes social, psychological, and behavioural changes that an individual undergoes as result of immigration" (Buscemi, Beech \& Relyea, 2011, p.149). Immigration clearly has a powerful effect on those who experience global relocation, and to be sure, balancing new and old foodways is an undeniable part of the acculturation process (Welsh \& Koç, 2011). In fact, this balancing process has been used by scholars to explain the process of integration (Romo \& Gill, 2012; Weller \& Turken, 2015). Unlike the phenomena of acculturation which can be explained in a neat and compact definition, integration is more of a process which scholars and governments alike have attempted to measure. The problem here is, despite a continued desire to measure integration, there is no standardized unit of measurement or agreed upon understanding of what the process of integration looks like (Wilkinson, 2013). As stated by Wong and Tezli (2013), "it [is] conceptually very difficult to define immigrant "integration" because it is not a unidimensional phenomenon" (p.10). 
For the purpose of clarity, I will provide a brief understanding of the term as outlined by Wilkinson, Wong, Tezli and Abu-Laban, but readers should take note that this is not a standardized or agreed upon definition. Wilkinson (2013) states that, integration is a reciprocal process where new-comers are incorporated into a new society. During the process, both the newcomer and host society change as a result of interaction with one another...the immigrant makes alterations to their behaviour to "fit in" while the host society changes as a result of the incorporation of newcomers (p.1).

Moreover, Wong and Tezli (2013)state that, "integration refers to the desirable way by which newcomers should become members of the receiving society and the society closely and intensely links its constituent parts, both groups and individuals" (p.10). Finally, Abu-Laban states,

integration encourages a process of mutual adjustment by both newcomers and society. This approach sets us apart from many other countries. Newcomers are expected to understand and respect basic Canadian values, but society is also expected to understand and respect the cultural differences newcomers bring to Canada (p.198).

In light of the three definitions provided, integration is ideally a two way process, where both the immigrant and the host country evolve and change, and such changes are believed to be beneficial for both parties.

Now one must question how to determine the success of such changes. I believe there is no single way to measure the success of integration due to the multifaceted nature of this phenomena. If you were to dissect or measure integration only by one specific factor, like economics for instance, then maybe "success" could measured. However, for the purpose of this MRP, I am dissecting the exchange of culture between the new immigrant within Canadian 
society and the subsequent changes of Canadian society at large. There are many complex dynamics in light of such definitions that the remainder of this section will discuss in prominent literature as it relates to acculturation, integration and food.

Academic discussions surrounding changing foodways and dietary modifications are prominent within the literature that looks at the process of immigration (Diner, 2001; Satia, et al., 2002; Wendel; 2008), but with that being said, it is more popular within settlement literature as related to food and changing foodways to examine assimilation rather than integration. Wendel's (2008) study looks at assimilation within the context of Norway and immigration, and argues that assimilation can be monitored by the "emphasis [individuals place] on maintaining the traditional cuisine, versus adoption of new food habits" (p. 377). In this way, food can be used as a way to highlight one's willingness to embrace the new culture which they are now a part of, but in contrast, it can also be used as a way to "maintain their marginalized cultures" within the majority society (Allen \& Sachs, 2007, p.9). Within the United States, Weller and Turken (2015) have used a similar idea (as well under the model of assimilation) when examining the immigration process of Latinos in Ithaca New York. Weller and Turken (2015) state that, "food consumption is an ideal tool for understanding the adaptive processes associated with immigration because food, as an essential need, defines the human experience" (p.58). In terms of monitoring integration through changing foodways, this has been examined in the case of Latin American immigrants who immigrated to Barcelona (Romo \& Gill, 2012). Aside from this particular study, there is little to no literature which speaks of integration as measured through foodways within the Canadian context. As such, this MRP will attempt to fill such a void and therefore will help to create a more robust and well rounded understanding of integration in Canada. This MRP aligns with the argument put forward by Wilkinson (2013) in that integration 
is a complex process that can not be understood by economics alone, and therefore, food is a unique and useful lens to help build a working definition of the phenomena.

\section{Women and food: gendered understanding of food purchasing, preparation and Consumption (PPC).}

Food purchasing, preparation, and consumption (PPC) is a highly gendered experience, especially when analyzed within a family context (Diner, 2001). Despite changing gender norms and shifting gender roles on a global scale, food PPC has historically, and continues to be, a feminized responsibility (Allen \& Sachs, 2007; Diner, 2001). At present, in most societies of the world, women continue to bear the "mental and manual labour" associated with food PPC (Diner, 2001, n.p). With that being said, there are several studies which look at immigration, gender, and food and have identified the changing structures of care and gender roles after immigration. (Diner, 2001; Gordon, 2004; Vallianatos \& Raine, 2008). Upon immigration to western countries, women have been pushed to find jobs outside the home and thus they have less time for domestic labour and men often become more active to help balance the burdens of PPC (Gordon, 2004). In contrast, the opposite effect has also been identified (Vallianatos and Raine, 2008). When families immigrate to a new country, men are noted to work outside the home (as a result of higher English proficiency) while women stay at home upholding domestic responsibilities. The stresses of working in a new country have proven to be an exhausting experience for immigrant men. When they return home, they do not have energy to contribute to food PPC. As such, male participation of food PPC is noted to decrease when compared to their home country while female food labour, as a response, increases. For instance, Arabic women and women from South Asia who migrated to Edmonton noted the extra time spent doing groceries when compared to "back home" (Vallianatos and Raine, 2008, p.365). Vallianatos and Raine noted that their participants in their home countries "did not have to leave their homes to 
shop because husbands or other extended family members often undertook this task, and vendors routinely sold food products door-to-door"(Vallianatos and Raine, 2008, p.365). In these examples, one can see a stark differences in gender roles as related to food PPC in a post immigration context, as presented by the scholars above. In general, "changes in food supply and in the tasks involved in food preparation [affects] women more heavily than men because of their primacy in matters involving cooking" or food PPC at large (Diner, 2001, p.5). The difference between changes in gendered participation (either an increase or a decrease) is likely the result of differing regions of origin (South-East Asia, vs. South Asia and the Middle East), and differing destination countries (United States, vs. Canada). It is crucial to contextualize both origin and destination country and the food culture to avoid essentializing female/male food PPC experiences within a post immigration context.

The discourses that solidify women's active roles in food PPC, also show the ways in which this work is perceived or valued from a societal perspective. Often, domestic work, which includes food PPC, is considered unskilled, and is undervalued (Anderson, 2000). It has also been argued that women's work within the home is so underappreciated that they are viewed as “appliances" or "mega-machines" of domestic labour (Davis, 2015). This imagery of appliances provides insight into the concept of duty. Just as an oven bakes, or a fridge cools, or a blender blends, a woman goes about her duties within the house, almost invisibly, routinely, and without thanks (Devault, 1991). As identified through the lense of marianismo, domestic work is simply a duty of a woman, especially within Latin American culture (Mandez-Luck, 2015).

Another noteworthy dynamic as related to gender and food is the contrast between the public and private spaces. This is especially interesting when held up against the lens of food and gastro politics. Despite women's prevailing role in food PPC within the home/private sphere, 
when one examines the interaction of women and food outside the home (like in commercial or food related business), women's participation declines significantly. Consequently, restaurant owners, farmers, food processors and large scale food manufacturing companies, are public spaces occupied primarily by men (Allen and Sachs, 2007). In conclusion, food work for men typically takes place outside the home as a paid position, while women's food work takes place within the home as an unpaid position (DeVault, 1991 \& Allen and Sachs, 2007). In fact, women are recorded to participate in two times as much housework or "domestic chores" as men, which is an "imbalance particularly marked by food labour" (Allen and Sachs, 2007, p.10).

Aside from nourishing and meeting the biological needs of the family, one must also examine the deeper semiotic meaning behind the gendered organization of food preparation and thus apply a gastro-political lens. To quote Appadurai, "food transactions" are carefully thought out or "manipulated" to carry messages between actors (1981, p.497). In the case of this MRP, the actors being examined are women (who are the main protagonist within the home as identified by the literature) while the other actors are the family members of these women. Now, for the purpose of this research, I will attempt to identify the symbolic messages a woman is trying passing along to her family through food PPC within the private sphere.

After careful research, with both scholarly source examination and my own personal interviews, I intend to argue that the message a woman is trying to convey through food PPC is that of culture. Whether this is a consciously or unconsciously constructed message, is up for debate, but what can be said with great certainty is that food is symbolic of culture. In the words of food historian Massimo Montanari, "food is culture" (2006, ix). The idea of cultural transmission through food, as mentioned above, is a popular idea that has been examined in a variety of contexts (Vallianatoes and Raine, 2008; Dubisch, 2014; Counihan, 2013). Here the 
relationship between women and cultural transmission through food is almost self explanatory.

The disproportionate activity of food related activities within the home are carried out by women, therefore, subsequently if food is a symbol of culture then women as the handlers of food, are therefore the messengers of culture. The idea of a mother, who has immigrated to Canada from Columbia, preparing arroz con frijoles (rice with beans) for her family, could easily be written off as a trivial activity that is done as part of her daily domestic duties. In reality, when an immigrant mother makes a conscious decision to buy, prepare, and, serve food from her home country to her family, she is wielding her autonomy and power to maintain a culture that is different from the one where she is now living (Counihan, 2013). Here, within the simple imagery of a plate of arroz con frijoles, one can identify the intersection of gender and culture when examined through the lens of gastronomy; and this may be a conscious or unconscious labour.

To quickly summarize the literature which was examined, it is clear that food is an undeniably gendered process, and within the home/private sphere and within the family, the woman holds the responsibility of food work. This responsibility is often considered part of a woman's domestic duties and goes unnoticed or underappreciated. Despite the invisibility of such work, a woman's food work in a post immigration household is hugely important in the transmission of culture from one generation to the next. In turn, the next section of this literature review will focus more attention on the concept of cultural maintenance through food.

\section{Food and culture: understanding food and culture in a pre and post migration context.}

Before launching into the idea of cultural maintenance within a post immigration context, it is necessary to elaborate further upon the interconnectedness of food and culture. Scholars agree that food is undeniably an element of culture (Appadurai, 1981; Devault, 1991; Diner, 
2001; Welsh \& Koç, 2001; Montinari, 2006; Holtzman, 2006; Owen Jones; 2007). This field of study in academia and dialogues at large started to enjoy a "universality of interest" throughout the 1970's (Pangborn \& Bruhn, 1971). However the connection between food and culture far out-dates the popularity of this theme within literature of the 20th century. As stated by Diner (2001), "Consumption of food has always been culturally constructed. What was tasty to one group invoked disgust and loathing in another" (p.3). Diner's statement brings forward three important points: 1) the interrelatedness of food and culture has a lengthy history which far surpasses academic discussion on the topic, 2) taste and taste preferences are culturally constructed, and 3) such taste preferences are divisive and create categories of those whom consume particular dishes, and those who do not, and this point speaks to the concept of identity. Perhaps one of the best examples which illustrates the three points taken from the works of Diner is that of escargot. Escargot is a classic example of a historically French cuisine (Eastham, Small \& Ross, et al., 2002) that brings together those who identify with this particular dish while simultaneously having the ability to disgust those who are unfamiliar with its chewy texture and strange presentation (Pangborn \& Bruhn, 1971). For clarification, I am not arguing here that all those who hold a French passport love escargot, nor am I denying the fact that many people outside of the French culture salivate when thinking of this particular dish. The point I am trying to make is when one thinks of escargot, they think of France. It is the power of this association between a single dish and an entire country that highlights the interconnectedness of food and culture.

Another important idea related to food and culture is that of regionality. As will be highlighted below, although there are similarities of food preferences and typical dishes (comida typica) throughout a nation, various regions within countries often have unique food cultures of 
their own, especially in larger countries such as Columbia or Mexico, (Askegaard, 1995). As such, one needs to be conscious of such regional differences when forming connections and drawing conclusions between food and culture.

While keeping this concepts in mind, scholars have also highlighted economic considerations of food and culture (Girard and Sercia, 2013). It is within the realm of economics that one must consider the financial accessibility of certain food items. For example, in Kenya a popular and culturally important dish is chapati and goat stew (Goyan Kittler \& Sucher, 2001). Despite the popularity of this specific dish and its appeal to those living within Kenya, poverty resulting in food insecurity plagues this East African nation (Barrett, 2010). As such, one must note that an individual's ability to participate in food culture is in a large part determined by their purchasing power. This theme will be discussed in chapter three. Ultimately, in accordance with Appadurai's gastro politics, when economics and food intersect, eating particular food items not only signifies that you are part of a particular culture, but it also has the potential to signify one's economic status within that particular culture.

Now that food and culture has been problematized, contextualized, and examined under the lens of gastro-politics, I would like to focus on the semiotic nature of food and its role within the home when people have migrated to a new country.

As the literature has shown, food is a powerful way to connect with one's home culture when immigrating to a new country (Vallianatos and Raine, 2008; Romo \& Gill, 2012; Weller \& Turken, 2015). The mobility of taste is perhaps one of the most fascinating aspects of food; food can transcend time and space and is not bound to any particular location, especially in light of our globalized capitalist system. Food in turn is a transnational phenomena, binding cultures together across the globe (Pollock, 2009). For instance, a notable body of literature is available 
which looks at the various uses of food purchasing and preparation by immigrant mothers (and in some cases fathers) to shape the identities of their children who are being raised outside of their home culture (Owen Jones, 2007; Weller \& Turken, 2014). It is within this context that one can explore the "conservation of taste" as a means of maintaining culture and forming identity (Diner, 2001, p.9). This concept of identity as it relates to food and culture is a theme that is important within scholarly literature and has proven an important theme within my own research. For example, as stated by Koc and Welsh (2001), "As we learn what to eat, how to eat, when to eat, we learn "our" culture, "our" norms and "our" values and through this process we learn who "we" are" (p.1). Ultimately, there is a perpetual interconnection of food, identity, and culture. The primary intent of the literature review presented has been to reaffirm the social realities associated with food PPC. Food as related to integration, acculturation, culture, and gender has been explored with this past chapter thus shedding light on the scholarly and academic works which inspired this particular MRP project. The next part of this MRP will create a methodological framework for the original research to follow. 


\section{Chapter Two: Methodology}

\section{Interviews and Qualitative Research}

As has been stated in the introduction of this MRP, the particular group whom I focused on was Latina mothers living in Toronto and surrounding areas. Based on the above literature review, the reader should have a sufficient body of information to understand why this is an important group to study, especially regarding their interaction and relationship with food in a post immigration context. My research was a qualitative and exploratory study using the method of one-on-one interviews.

My research was conducted during the Spring/Summer term of 2016 academic year. During this period I conducted six interviews with participants who fit the inclusion criteria: Spanish speaking, Latina mothers, who immigrated to Canada from North, Central, and South America. Of the six participants interviewed, one mother was originally from Guatemala, three mothers were from Mexico, and two mothers were from Columbia. Each interview lasted for approximately one to one and one-half hours. Interview themes and interviewer-participant conversation was prompted by pre-written questions (approved by the Ryerson University ethics board which can be found in the appendix) but the interviews took a natural and organic course as participants were free to talk about any topic they found personally relevant. The time allotted to each participant seemed adequate for understanding and grasping major themes of these women's lives as related to food, migration, acculturation, and integration. All women interviewed gave informed consent, and were given the option to pull out of the study, for any reason. Interviews were conducted in coffee shops, libraries, and community spaces which provided safe, public, and neutral locations for both the participant and myself. Each interview was recorded, with permission of the participant, and later transcribed and coded as a means of 
outlining thematic patterns (Devault, 1990; Vallianatos \& Raine, 2008). After coding and identifying themes, results were compared and contrasted with relevant literature on the topic. After compiling my themes and analysing quotes to fit within thematic patterns, I invited two of my participants to read the findings section of this paper to ensure proper representation. The two participants asked are fluent in english, while participants with lower levels of english proficiency were not asked to part of this member checking process.

My methodology took an entirely qualitative and exploratory form, and it should be noted, that themes and ideas extracted from this study are not meant to draw generalizations about the Latino community as a whole, but rather, to shed light on some important ideas and themes within the community that have yet to be explored.

Although qualitative research is subjective and has greater room for researcher bias when compared to quantitative research, it proved to be a highly useful methodology for the purpose of this study. In justifying my use of qualitative research, it is important to iterate the purpose of quantitative research so one can see why I determined this methodology to be ill-fitting for the purpose of this study. Quantitative research seeks to explain the social world through numerical projections such as "percentages, ratios, probability values, variance ratios, etc" (King \& Horrocks, 2010, p.8). On the other hand, although qualitative research also aims to understand and explain the social world, such explanations must be presented without numerical aids; and as Kvale (1996) states, "if you want to understand how people understand their world and their life, why not talk to them" (p.1). For the purpose of this MRP, I wanted to understand personal experiences as related to immigration and food to try and better understand a specific feature of integration and acculturation in Canada. As such, one can better express personal experiences through words and stories rather than through numbers. I wanted, and needed, to share the voices 
of Latina immigrant mothers in Canada as they are a group which is yet to have a voice within academic literature. Therefore, within the tradition of qualitative epistemology, I utilized the method of interviews (King \& Horrocks, 2010, p.17).

Despite the usefulness of qualitative research, I must note the fact that I am an outsider of this community thus meaning there could be some elements of misrepresentation within the findings extrapolated from this methodology. I am Canadian born, I am not ethnically part of the Latin American community, and I do not have children. In trying to capture the essence of this particular group while not being from within the group, undeniably poses challenges. The idea of misrepresentation and recognition of my outsider status is related to the concept of standpoint theory. This postmodern concept ought to be referenced and acknowledged by all academics who intend to conduct qualitative research. As standpoint theory states, an individual's perspective is shaped by her/his lived experiences within a hierarchical social system (Neuman, 2011). As such, although a researcher could be accurately quoting a participant within a qualitative interview based study, the researcher's interpretation and analysis of such quotes can we skewed by their own personal understandings of the world around them. Misrepresentation is a major risk within qualitative research (Neuman, 2011). It is crucial to be aware of such risks in order to mitigate and minimize the potential for misrepresentation by understanding where one stands within a greater social framework. For example, although I am not part of this community, I am fluent in Spanish, I am a woman, I work as an english teacher with Latinos in Toronto at the Centro Para Gente de Habla Hispana, my partner is Colombian, and I have lived in Latin America for extensive periods of time. As such, Latin American culture is familiar to me and I entered into the interview process aware of the group which I was engaging with. Furthermore, all interview questions were formulated with cultural relativity and cultural sensitivity in mind. It 
can be argued that being outside of the culture, while simultaneously being extremely familiar with the culture in question, actually provides a unique lens with which to conduct research (Kanuha, 2000; Dwyer \& Buckle, 2009). In fact, there are challenges with being an insider and an outsider when performing qualitative research, but there are benefits and strengths associated with both positions (Watson, 1999; Armstrong, 2001; Dwyer \& Buckle, 2009). For instance, the "space between" highlights a unique researcher position which "challenges the dichotomy of insider versus outsider status" (Dwyer \& Buckle, 2009, p.60). In the words of Dwyer and Buckle (2009),

as qualitative researchers we have an appreciation for the fluidity and multilayered complexity of human experience. Holding membership in a group does not denote complete sameness within that group. Likewise, not being a member of a group does not denote complete difference. It seems paradoxical, then, that we would endorse binary alternatives that unduly narrow the range of understanding and experience (p.60).

The framework of "the space between" presented by the aforementioned scholars is a useful tool for understanding where I personally fit in relation to my research participants. This framework ought to be considered by others who plan to engage with qualitative methodology.

The final point I would like to note within this chapter on methodology is related to potential conflicts of interest between myself and my research participants. This is a common phenomena within qualitative research and it is often hard to completely mitigate all conflicting interests when participants are found through shared personal social networks. For myself, two of my participants were mothers of friends, three were work colleagues of my mother, while I was put in contact with the final participant through my superior at the Centro Para Gente de Habla Hispana. Although I had never personally met any of the participants before conducting 
the interviews, all participants came into contact with me through shared personal connections thus meaning participants may have felt a sense of obligation to help their colleagues or friends who approached them on my behalf. As outlined by King and Horrocks (2010), when there is the potential for conflicts of interest, it is necessary for the researcher to create a clear and definitive boundary between your role as a researcher and your external/non-academic self which is somehow connected to the participant (albeit, loosely connected).

Overall, qualitative research methodology using interviews as my primary method followed by thematic coding proved to be highly effective in gathering information as related to the gendered immigration experience examined through the lens of food and integration.

The next chapter of this essay will focus on the findings of the six interviews conducted to examine how their personal experiences configure with the existing on this topic. Readers should note that participants names were changed for the purpose of confidentiality, but the remaining information such as nationality, reason for immigration, years they have lived in Canada, and information regarding their children and husband are accurate. 


\section{Chapter Three: Original Research and Finding}

\section{Research Participants}

Before discussing my findings from the interviews conducted, I feel it is important to highlight key information about the participants so that the reader can compare and contrast key identifying elements about the participants. As such, below I have created a participant's information chart so that the reader can familiarize themselves with the participants to better understand the analytical discussions and thematic ideas that follow.

\begin{tabular}{|c|c|c|c|c|c|c|}
\hline Pseudonym & $\begin{array}{c}\text { Country of } \\
\text { Origin }\end{array}$ & $\begin{array}{c}\text { Year of } \\
\text { Immigration }\end{array}$ & $\begin{array}{l}\text { Reason for } \\
\text { Immigration }\end{array}$ & $\begin{array}{c}\text { Canadian } \\
\text { Settlement } \\
\text { Location }\end{array}$ & $\begin{array}{l}\text { Country of } \\
\text { Birth of } \\
\text { Children }\end{array}$ & $\begin{array}{c}\text { English } \\
\text { Proficiency }\end{array}$ \\
\hline Maria & $\begin{array}{l}\text { Columbia } \\
\text { (Cali) }\end{array}$ & 2000 & $\begin{array}{l}\text { wanted better } \\
\text { education } \\
\text { opportunities } \\
\text { for her } \\
\text { daughter }\end{array}$ & $\begin{array}{l}\text { Walkerton, } \\
\text { Ontario } \\
\text { Currently in } \\
\text { Kitchener, } \\
\text { Ontario }\end{array}$ & $\begin{array}{l}\text { Columbia } \\
\text { (1 daughter) }\end{array}$ & fluent \\
\hline Ingrid & $\begin{array}{l}\text { Columbia } \\
\text { (Bogata) }\end{array}$ & 2009 & $\begin{array}{l}\text { relocated for } \\
\text { safety reasons }\end{array}$ & $\begin{array}{l}\text { Toronto, } \\
\text { Ontario }\end{array}$ & $\begin{array}{l}\text { Columbia } \\
\text { ( } 2 \text { sons, } 1 \\
\text { daughter) }\end{array}$ & $\begin{array}{l}\text { high- } \\
\text { beginner }\end{array}$ \\
\hline Maji & $\begin{array}{l}\text { Columbia } \\
\text { (Bogata) }\end{array}$ & 1998 & $\begin{array}{l}\text { political } \\
\text { refugees }\end{array}$ & $\begin{array}{l}\text { Toronto, } \\
\text { Ontario }\end{array}$ & $\begin{array}{l}\text { Columbia (1 } \\
\text { son, } 1 \\
\text { daughter) }\end{array}$ & $\begin{array}{l}\text { high- } \\
\text { beginner }\end{array}$ \\
\hline Camilla & $\begin{array}{l}\text { Guatemala } \\
\text { (Guatemala } \\
\text { City) }\end{array}$ & 1970 & $\begin{array}{l}\text { wanted better } \\
\text { job and } \\
\text { economic } \\
\text { opportunities }\end{array}$ & $\begin{array}{l}\text { Toronto, } \\
\text { Ontario }\end{array}$ & $\begin{array}{l}\text { Canada (2 } \\
\text { daughters, } 1 \\
\text { son) }\end{array}$ & intermediate \\
\hline Fabiola & $\begin{array}{l}\text { Mexico } \\
\text { (Vera Cruz) }\end{array}$ & 2002 & $\begin{array}{l}\text { job relocation } \\
\text { within } \\
\text { company }\end{array}$ & $\begin{array}{l}\text { Toronto, } \\
\text { Ontario }\end{array}$ & $\begin{array}{l}\text { Mexico (2 } \\
\text { daughters) }\end{array}$ & $\begin{array}{l}\text { high- } \\
\text { intermediae }\end{array}$ \\
\hline Milu & $\begin{array}{l}\text { Mexico } \\
\text { (Mexico } \\
\text { City) }\end{array}$ & 2008 & $\begin{array}{l}\text { job relocation } \\
\text { within } \\
\text { company }\end{array}$ & $\begin{array}{l}\text { Milton, } \\
\text { Ontario }\end{array}$ & $\begin{array}{l}\text { Canada (3 } \\
\text { daughters) }\end{array}$ & fluent \\
\hline
\end{tabular}

* Please Note: English proficiency was an estimated account made by me based on my experiences teaching english to Latin Americans and my english teaching certification (TEFL).

As you can see, my participants differ significantly and such differentiations were noted when looking at thematic patterns of immigration, integration and acculturation. 


\section{Conceptual Themes and Findings}

The first theme I would like to discuss which came up within the interviews was the reason the participants and their families migrated to Canada. Although the reason for migration is not directly related to food, there is a unique connection between this particular factor and the participants relationship with food PPC in the Canadian context. Take for instance, Maji, a Colombian immigrant whose family fled to Canada as refugees. Maji remarked, "we did not want to come here but this country was our option for safety. I left all things I loved and all people I loved. When we came here we had nothing and we knew no one". In the case of Maji's family, they were forced to pack-up and leave the country in only two weeks after threats were sent to her husband. Maji's husband was a successful politician in Columbia, but after a change in municipal government, their family was no longer safe. In contrast, Milu and her husband had always dreamed of moving to Canada. Milu told me that when she and her husband first starting dating, he fantasized about doing his Master of Business Administration at the University of Toronto. In 2008, Milu's husband was offered an intercompany transfer to Burlington, Ontario and without hesitation they packed up their lives in Mexico City and moved to Canada. Milu remarked that "Canada is a beautiful country to raise your children in and very family oriented...that is why we wanted to come here". After migrating to Canada, Milu and her husband had three children, all of whom are under the age of seven currently. When comparing these statements by Maji and Milu, it is clear that they immigrated to Canada for significantly different reasons, and interestingly, their desires to be part of Canadian society differs dramatically. The former came to Canada out of forced circumstance while the later chose to immigrate here as part of a long-term personal dream. These two examples, are of course, extreme opposite reasons for migration to Canada; but, such positions of opposition create a 
unique window with which to compare the phenomena of integration and acculturation through food. For instance, Milu stated, 'I'm not your typical Mexican. I try to avoid cooking mexican food regularly because it's not very healthy. It has too much oil, too much cheese, too much meat." Milu told me that she tries to cook whatever is healthy not whatever is Mexican. In contrast, when I asked Maji about the frequency of Colombian food PPC, she stated, "we eat colombian food always. Everyday. Of course... it's our favourite”.

The responses provided by Milu and Maji inspire a conceptual framework that further research ought to explore, and with which my research can only begin to speculate. When forced to leave a country, you aspire to maintain food habits of your home country when compared to those who willingly and happily migrate to a new country. For example, Camilla relocated from Guatemala to Canada willingly and voluntarily but would have preferred to stay in Guatemala if there were better economic opportunities. Camilla told me, "I could barely afford the bus so sometimes I would have to walk two hours to work and two hours home. We could not afford to stay there. We wanted to come to Canada for a better life." Camilla and her husband relocated to Canada in 1970, when immigration from this region was not yet common (Veronis, 2010, p.6). Camilla told me, "I was happy to be here but I was so sad too... I would cry and my husband was my only friend". When Camilla came, she noted that it was hard for her because they were outsiders and she rarely heard "her language" spoken on the streets. For Camilla, her immigration process to Canada seems to straddle the line between immigration out of necessity and immigration out of choice. Interestingly, and in accordance with the connection between food PPC and migration discussed above, Camilla's food preferences in a post migration context also straddles the line between Guatemalan cuisine and Canadian/North American cuisine. Camilla stated that, "When we were stable with money we ate hamburgers, french fries, hot 
dogs, but always, I do my frijoles. I would mash them, fry them, bake them... just like home. [My family] love frijoles". The other three participants engage with both North American style cuisine and cuisine from their home countries, but at varying degrees. Below I have placed each participant on a continuum of food PPC as related to their home countries food PPC and Canadian/North American style food PPC for an effective visual which can be used to better understand the integration and acculturation experience as a whole.

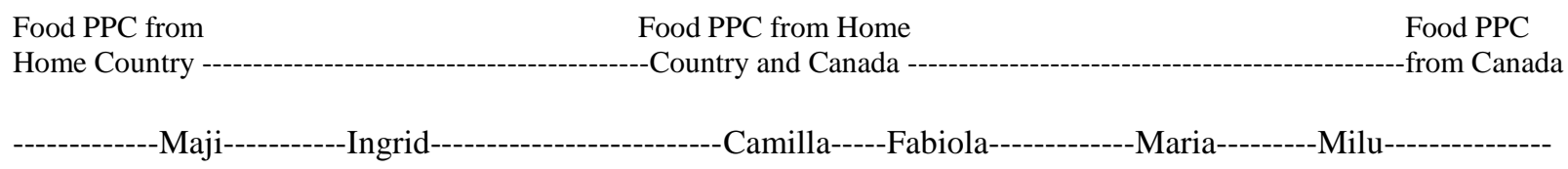

I created this visual aid to help the reader track the participants food PPC as they engage with food from their home country and North American cuisine. It should be noted by the reader that the participants were plotted on this scale based on their responses within the interview and this scale is symbolic of their food PPC habits and does not reflect exact or quantifiable measurements of any sort. This chart ought be be used by the reader to orient themselves and familiarize themselves with the participant's food PPC habits.

The next theme I would like to explore is that of food accessibility. Depending on factors like year or time of migration, proximity to grocery stores, and economic stability, maintaining food PPC habits from one's home country allows for varying levels of access to particular food related activities.

For instance, for Camilla who came to Canada in 1970, when migration from Latin America was not common [as identified by Veronis (2010)], her ability to find ingredients to prepare dishes similar to classic Guatemalan cuisine proved to be a challenging task. Camilla 
stated, "When we came here, we don't have nothin' like from my country... so we ate spaghetti... one can in specific was really good... We ate that cause we don't know what to eat...". Camilla talked about eating bread and ham and spaghetti, spending only $\$ 15.00$ per week on groceries. Within this specific scenario, one can identify many reasons why Camilla's food PPC habits had changed significantly when first arriving to Canada and she was unable to buy or prepare food which was culturally familiar to her. Firstly, in 1970, grocery stores in Canada did not have a plethora of Latin American specific ingredients as the demand for such items would not have been great. However, as immigration from Latin America to Canada started to increased throughout the late 1970's and into the 1980's (mirroring the political instability of the region), Latin American ingredients started to become more visible in grocery stores. Camilla explained that, "I could start to see our food [in Toronto] in 1982... like frijoles! You know Spadina? They had a guy over there who was portuguese and he brought food from Mexico. This food is a little similar to Guatemalan food. So we took it! Sometimes he had tortillas. It wasn't often. When we saw it, we take it!". As Camilla was my only participant who immigrated during the second wave of Latin American immigration to Canada, her responses provide a unique insight into food accessibility (or lack thereof) at a time when Toronto grocery stores simply did not have the ingredients she wanted. All of the other participants who immigrated to Toronto or the GTA in the late 20 th century or the early-mid 21 st century did not identify this as a problem.

In contrast, one of my participant's immigration experience presents a unique situation with which to analyze food accessibility in a post migration context. For instance, Maria immigrated to Canada from Cali, Columbia in 2000 and unlike the rest of my participants who immigrated to large metropolitan areas in Ontario, Maria immigrated to the small town of Walkerton, Ontario. Not surprisingly, for Maria, food PPC habits as related to Colombian food 
was significantly limited due to her rural settlement location. Maria told me, "if I wanted to cook or prepare a colombian style meal, I would need to buy most of my ingredients from Kitchener/Waterloo which meant I had to plan and I had to be willing to spend more money." Maria expressed a negative tone toward those who felt the need to maintain their food culture from "back home". Maria said, "eating plantain or cooking empanadas is a luxury activity. All I worried about was that my daughter was healthy. It did not matter if she was eating Colombian style food." If fact, similar to Milu, Maria expressed the unhealthy nature of dishes from Latin America, and as such, she explained that she tried to stay away from Colombian cooking as much as possible. For Maria, her decision to live in rural Ontario and her food PPC habits which did not frequently include Colombian style dishes, reflects her overall integration experience. In general, Maria told me that she tries to stay away from Colombians as much as possible in Canada, and as such, her lifestyle and cooking choices very much reflect that decision. Maria speaks english in her home (to her Canadian husband), she speaks english with her daughter (who is also married to a Canadian), and she told me that other than her family, she does not interact with Colombians. For Maria, the unavailability of Colombian ingredients while living in Walkerton did not prove to be a problem, but rather, was symbolic of the distance that Maria wanted from the culture as a whole. Maria told me that she became curious about Canadian style cooking and was far more interested in mastering the art of "making the perfect pie crust" or learning how to use Canadian root vegetables in soups and stews. None the less, Maria made it clear to me that she was proud to be Colombian, and she was taking the best of Colombian culture and the best of Canadian culture and fusing them together in her everyday life. For Maria, Colombian food was not healthy, and therefore, she chose to cook other styles of food, "with a 
Colombian twist". In contrast, my interview with Ingrid, who as well immigrated from Colombia, brought forward different views.

Ingrid settled in Toronto in 2009, and for her, living in a large city meant that she could maintain Colombian food PPC habits. In fact, one of Ingrid's first jobs when arriving in Canada was at a Colombian grocery store on Bathurst Street. Ingrid stated, "When I came to Canada, I tried to find the same things as in Columbia. And thank God I found a lot of stuff similar to Columbia! I cook very Colombian here! I've been here eight years and I still prepare Colombian food. Everyday I cook rice with potatoes, chicken, meat, potatoes and onions ". For Ingrid, Colombian food is highly important to her everyday life and she spoke to me about her desire to find bread here as good as in the bakeries back home. My interview with Ingrid was conducted mostly in Spanish (despite her ability to speak in english) because of her general comfort talking in her own language. With her children, Ingrid only speaks in Spanish and she told me most of her friends in Toronto are Colombian. The stories of Maria and Ingrid highlight unique and distinct connections between food accessibility, food PPC, and acculturation and integration.

Finally, food accessibility and food PPC habits related to economics was a topic that all participants referenced. Excluding Camilla whose story is unique due to her much earlier date of immigration, all participants could afford to buy Latin American food products if they so chose, thus meaning, dietary changes when entering Canada were more reflective of personal desire to modify one's diet rather than economic inability to buy certain ingredients. Although the literature available on this topic does talk about economic hardships related to food PPC, within my study, this was not a factor that seemed to affect food PPC habits.

Another important area of focus that was brought forth within the interviews was that of food PPC during holidays or special activities. Even the participants who identified that their 
food habits and food PPC had changed almost completely since immigration into Canada reported that for holidays and special cultural events they still preferred to prepare foods from their home country. For example, Fabiola who is originally from Vera-Cruz Mexico talked about her cooking habits being "not very Mexican" but that around Christmas and New Year's she liked to prepare all the foods that she enjoyed from "back-home". One dessert dish that both Fabiola and Milu referenced is called Rosca de Reyes which is a sweet fruit filled cake with a plastic baby Jesus inside one of the pieces. Fabiola told me that, "ever since we came to Canada we make sure that every new year's we have this cake. It tastes like home”. Similar sentiments were shared by Milu who stated, "[Rosca de Reyes] is one of our kids favourite things. I think my daughter still has the baby jesus hidden in her room somewhere from last year!". For these two participants, Mexican food PPC was not prominent, but when the holiday season came around, food was served as a way to reconnect with their Mexican culture. Holidays are sentimental times when people typically want to be with their families, and as such, by buying, preparing, and consuming foods from back home, these participants are bridging the geographic distance between themselves and their families.

Another theme arose when examining food PPC habits during holidays which was the incorporation of North American style foods into their traditional holiday dishes. All participants told me that they learned how to cook turkey (and other assorted holiday dishes like cranberry sauce and stuffing) for both thanksgiving and Christmas which is a dish central to Canadian festive menus. Interestingly, Turkey in its North American preparatory form, was already part of the Mexican holiday food regime which may have to do with Mexico's cultural similarities as being part of North America and its close relationship with the United States. Two participants from Columbia shared stories of altering the turkey preparation to a more familiar cooking style 
in their first years in Canada. For instance, Maria told me that she proudly cooked and served a turkey stew for her daughter and her Canadian friends. Maria's Canadian friends were "confused" at first but they said they loved the dish. Maria remarked, "I know how to cook a Turkey Canadian style now". In general, recipe alteration was a common theme both within and outside holiday food preparation. As participants interacted with new ingredients while simultaneously lacked ingredients familiar to them, women were continuously forced to improvise. For instance, tamales are another important holiday cuisine popular across Latin America which are wrapped and cooked inside a banana leaf. Two participants talked about the struggle in finding a banana leaf "like back home" to make tamales for Christmas. As such, the participants spoke of a substitution of banana leaves "like back home" for "asian style banana leaves". Maria called these tamales "Filipino tamales". Not only is this example speaking to women's need to be flexible with their holiday food PPC in Canada, this imagery of a "Filipino tamale" is also symbolic of the multicultural atmosphere that is Toronto and the greater Toronto area.

Overall, discussions regarding holiday food PPC was exceptionally telling of the participants' desire to maintain their home culture through their "comida typica" (typical food) while simultaneously immersing in Canadian style holiday foods. Holiday food PPC is a perfect snapshot of integration (as defined in the previous section) as an exchange of cultures occurs.

Another interesting area of focus within these interviews which supports the ideas of Vallianatos and Raine (2008) was the exchange of culture from mothers to their children through food which contributes to the concept of gatekeepers. The gatekeeper phenomena is defined as the mother's role in "[balancing] the need to impart family and community values via traditional foods and cuisines, with adjusting to life and foodways in Canada" (Vallianatos \& Raine, 2008, 
p.357). In this context, all mothers expressed a desire for their children to know and taste the foods of their heritage, but a noteworthy difference was that while some mothers wanted these dishes to be their primary source of food intake, other mothers felt that these dishes were "sometimes" meals that could be used as cultural and learning opportunities for their children. For instance, while Maji and Ingrid serve Colombian food almost daily, Milu and Maria rarely serve "comida typica", although they do incorporate elements of Mexican and Colombian style cooking into commonly prepared dishes like stir-frys and pasta dishes. Milu reported that her favourite meals to prepare are Italian style cooking, and that her children mostly learn about Mexican food when her mother-in law comes to visit from Mexico City or when they return to Mexico on holiday. For Maria, although she stays away from Colombian food in general (primarily for health reasons as they switched to a fresh and organic diet after her daughter was diagnosed with cancer in 2011), she will prepare Colombian food occasionally as a means of cultural transfusion. For instance, when we met for this MRP interview, she had prepared Colombian frijoles con arroz (beans with rice) for me to try so she could share the tastes of Columbia. Maria told me her preparation style was significantly different in that she chose to boil the beans and rice instead of fry them, which would be the typically Colombian form of preparation.

Here, within the exploration of the gatekeeper phenomena and cultural transfusion, I would like to highlight another speculative conclusion about food, acculturation and integration. For instance, the mothers who choose to serve "comida typica" as the primary meals within their homes also had lower proficiency in English and reported that their friends were primarily from their same culture or from other Spanish speaking countries. Here, one can identify a connection between maintaining one's culture through food and lower levels of acculturation and 
integration. In contrast, those who less frequently engaged with "comida typica" had higher levels of English proficiency and engaged with a wider variety of peoples and cultures outside of their own. When I asked Milu about her friend group, she reported that most of their friends were "Canadian" and even when they spent time with a Venezuelan couple, they still spoke in English to one another. As such, further research needs to be conducted to confirm such a connection between food PPC habits and integration and acculturation. A similar study could be done using large-sample quantitative research to create more generalized findings. Of course, due to the size of my study, I do not have sufficient evidence to prove this connection, but my work can be used as a stepping stone for further research to either prove or disprove the connection which I have outlined or enhance their own findings.

The final theme which I would like to discuss is that of gender in light of the theoretical lens of marianismo and machismo. As elaborated upon earlier, marianismo is highly useful when examining gendered relations within the context of Latin America. As defined earlier, marianismo provides a framework with which to understand Latin American women's self sacrificing and nurturing role within the home while men maintain a position of authority and dominate the public sphere (Mandez-Luck and Anthony, 2015).

Applying this framework to the relationships between men and women once they are removed from Latin America and placed within the Canadian context needs to be explored. Of the six participants interviewed, all the mothers were married or in a long-term, heterosexual partnership. All participants except for one were with men from Latin America while Maria had married a Canadian man (of Finnish ancestry) after immigration. All the participants interviewed come from different socioeconomic backgrounds, have different levels of education, varying levels of English proficiency, live in different locations in the GTA, and have significantly 
different relationships with comida typica and food PPC habits. With that being said, despite all the variables that were uncovered within these women's lives, they shared a telling commonality between the six of them: each woman was responsible for all the food preparation within the household. When asked if their partners and husbands participated in food PPC, all of the women responded that they did not. Maji reported that it was her job as the wife and mother to feed her family. Ingrid stated, "I like to cook! In Columbia my mother taught me how to cook, and I taught my daughter how to cook. It's normal for me". Camilla stated that, "my husband will clean the house, make the bed, mop the floor, but the kitchen is mine". Fabiola giggled when I asked if her husband can cook and then replied with a simple "no". Maria, even though she is married to a non-Latin America, is the primary cook in the house and stated that sometimes her partner will barbeque. And finally, when I asked Milu about her husband's abilities in the kitchen she said, "Pancakes! He can make pancakes! He makes them for the girls on Saturdays and Sundays! But that is all he can do."

As reported by Allen and Sachs (2007), this is not a unique phenomena, and "today, in most societies women continue to carry the responsibility for the mental and manual labor of food provision - the most basic labor of care" (p.1). Women, historically and today, are the providers of food and nutrition for their families and my research fits into this larger field of gendered and nutritional/food research. However, a quality which makes this finding specific to Latin America is that, none of the participants had any visible or expressed feeling of resentment towards this particular responsibility. For these women, cooking was a normal duty that they did to support their families well being and was something, that as a women, they ought to do. This belief is confirmed through questions regarding gendered attitudes and their children. For instance, I inquired with Ingrid about her three children (who are eighteen, twenty-three, and 
twenty-nine) and she reported that her daughter could cook while her sons did not need to learn. One of her sons who was in the room during the interview commented that his girlfriend (who was Argentinian in background) did all the cooking for him, and he finds cooking an attractive and necessary quality in a partner. When I inquired with the other participants about teaching their children how to cook, all participants shared that they had taught their daughters to cook, while only one reported teaching their son how to cook. Even so, Camilla's son who was taught how to cook married a woman from Guatemala and now, she reported, he rarely participates in cooking within his own home. In Latin America, cooking and food PPC is a normal part of a woman's gendered responsibilities and she is socialized to embrace this role through society at large. Evidently, even once a woman is taken away from the geographical context of Latin America, these ideals and gendered roles are upheld and then passed on to the next generation. Consequently, this passage of gender roles from one generation to the next is part of a woman's role as a gatekeeper and transfuser of culture.

The purpose of this section was to explore the original research uncovered within six interviews with six Latin American women in the Spring/Summer of 2016. Yet again, I would like to iterate that the research conducted for this MRP is not explanatory of an entire community, but rather, is exploratory and unveils interesting themes and points of exploration for further research on Latin American in Canada and the integration and acculturation process. The last chapter of this MRP will briefly wrap up the major ideas, themes, and findings of this MRP. 


\section{Chapter Four: Conclusion and Closing Remarks}

After engaging with this MRP and diving into the academic literature available as well as my own original research, I hope that the reader now embraces the remark "you are what you eat" from a social perspective. Food is a social phenomenon that can be used as a tool to understand the social realities of individuals as they interact with the world around them. The primary purpose of my research was to use food and the food PPC habits of Latin American women as a mirror to better understand the process of acculturation and immigration in Canada.

To achieve this goal, I performed extensive academic literature analysis to understand the rich body of scholarly work available which discusses food as related to immigration, gender, and culture. In doing so, I looked at the sources available through two pertinent lenses: gastropolitics and marianismo/machismo. After analyzing and problematizing the sources within the field, I was able to identify key gaps within the literature that my original research can begin to mend, and as well, intersectionalities between such literature that my research has begun to bridge. All in all, the literature review within this paper can now be used as an effective starting point for any future scholar intending to write about food as related to immigration and gender within the Canadian context.

On top of a rich literature review, I conducted my own original research in the Spring/Summer of 2016 with six participants from Latin America. All participants were women, mothers, and born in Latin America (Mexico, Guatemala, and Columbia). My findings from these interviews were exploratory and uncovered interesting themes which further research ought to explore. Firstly, I found a relationship between reason for immigration and food preparation and PPC habits in the Canadian context. Those who were forced to leave their home countries seemed to maintain their food PPC habits once they settled in Canada while those who chose to 
leave their home countries did not engage with comida typica with the same frequency.

Secondly, food accessibility and food PPC habits related to economics was a topic that all participants referenced. In general, dietary changes when immigrating to Canada was reflective of a personal desire to modify one's diet rather than economic inability to buy certain ingredients. As such, this study was not telling of a lack of accessibility to certain ingredients, but rather, a desire or lack of desire to buy certain types of foods. Thirdly, themes regarding holiday food preparation were explored. Discussions about holiday food and comida typica was highly telling of culture. Even those participants who distanced themselves from comida typica once they immigrated to Canada still felt it was important to engage with food from their home country during the holiday season as a way to stay connected to their home culture and teach their children about their heritage. Finally, the most interesting finding as related to marianismo and machismo was that of food preparation being completely a duty or responsibility of the woman within the home. Despite the varying countries of origin, reasons for migration, language proficiency or relationship status, all of my participants were the primary buyers and cooks of food for their families. Moreover, when participants were asked about this particular role, all of them replied that this was their duty as a mother and woman within the family.

The limitations of this study are prevalent and one must be careful how they use the findings of this MRP. For instance, due to the small size of the participants interviewed, I cannot make definite statements about any of my findings. Simply put, the findings presented in this MRP are merely stepping stones for larger research studies. Another significant limitation of my study is that I used participant from different countries of origin, who immigrated for different reasons. For a more uniform or explanatory research project, I would suggest participants from a more homogeneous pool. 
Another necessary point of conversation is related to my methodological model which was highly influenced by the research presented by Vallianatos and Raine (2008). Of course, due to the time limitations, I was unable to conduct as in depth a study as they completed. For instance, Vallianatos and Raine were able to conduct interviews with 36 different women and these interviews with women specifically from South Asia and Arab communities were part of a larger study “examining adult women's migration experiences” (p.358). Aside from the size and scope of their research, my methodology follows a very similar path. If I were to have more time to conduct this MRP, I would have tried to interview a similar number of participants as Vallianatos and Raine. Perhaps this is one of the most notable limitations of my study. Moreover, another potential limitation would be that I interviewed latina women from very different socioeconomic statuses, who immigrated to Canada for a variety of different reasons, from three different countries. The variabilities of participants needs to be kept in mind when exploring the settlement experience as related to food within this MRP, and in later sections of this paper, I highlight that my findings are not intended to be explanatory of the latina's as a whole, but rather, is exploratory of those whom I interview. With more time and potential funding, I believe a research participant group from similar economic statuses, who immigrated to Canada for the same reasons, and finally, from the same country of origin, would provide a ripe opportunity for explanatory conclusions rather than exploratory dialogues.

The final point I would like to make is regarding policy implications. Of course, research within the field of immigration ought to have the intent to make positive and meaningful change to better the lives of those experiencing this challenging process. No matter the reason for immigration, each experience presents its own unique challenges. One recommendation in which I would push for is that of availability of comida typica within food banks. As mentioned earlier, 
Latin Americans in Canada are an impoverished group, and therefore, are common users of food banks and publicly provided food services (Rush, et.al, 2007). After careful research which examines the importance and symbolism of comida typica, food banks ought to try and meet these symbolic food needs as well as the basic nutritional needs of their users.

In general, this MRP was an exploratory project which uncovered useful and underdeveloped themes as related to food, acculturation, integration, and gender within the Canadian context and the Latin American community. I urge the reader to always take note of the symbolic nature of food and embrace the words of Jean Anthelme Brillat-Savarin; "Tell me what you eat, and I shall tell you what you are". 


\section{Appendix}

\section{Interview Questions}

1) When did you immigrate to Canada?

2) Why did you immigrate to Canada?

3) Where were your children born?

4) When you arrived in Canada, what is your first memory related to food?

5) When you first arrived, did you look for grocery stores that supplied foods/ingredients from home? If so, were these stores a) affordable b) accessible/close to where you were living. Do you still shop at these speciality stores?

6) Where did you buy most of your groceries when you first arrived? Where do you buy them now?

7) What was your impression of North American grocery stores? How do you feel about North American grocery stores now?

8) Did you (and do you still) attempt to cook traditional dishes from "home"?

9) If so, how often and how frequently did you prepare these dishes?

10) What did you children think about food from "home" compared to food from Canada

11) Did you ever have to modify cooking from "home" because of challenges such as lack of ingredients?

12) Are there special dishes you prepare for holidays? Did you prepare these dishes when you arrived? Do you still prepare them? Do you children like these dishes? 


\section{Bibliography}

Abu-Laban, Y. (1998). Welcome/STAY OUT: The contradiction of Canadian integration and immigration policies at the millennium. Canadian ethnic studies, 30(3), 190.

Allen, P., \& Sachs, C. (2012). Women and food chains: The gendered politics of food. Taking food public: Redefining foodways in a changing world, 23-40.

Anderson, B. (2000). Doing the dirty work?: The global politics of domestic labour. Palgrave Macmillan.

Appadurai, A. (1981). Gastro-politics in hindu south asia. American Ethnologist, 8(3), 494-511.

Armstrong, M.S (2001). Women leaving heterosexuality at mid-life: Transformation in self and relations. Unpublished doctoral dissertation, York University, Toronto, Ontario, Canada.

Askegaard, S., \& Madsen, T. K. (1995). European food cultures: an exploratory analysis of food related preferences and behaviour in European regions. MAPP.

Barrett, C. B. (2010). Measuring food insecurity. Science, 327(5967), 825-828.

Buscemi, J., Beech, B. M., \& Relyea, G. (2011). Predictors of obesity in Latino children: acculturation as a moderator of the relationship between food insecurity and body mass index percentile. Journal of Immigrant and Minority Health, 13(1), 149-154.

Counihan, C. M. (2013). Food and gender. Routledge.

Davis, A. J. (2015). Reading the Strange Case of Woman-as-Appliance: On Transfigurations, Cyborgs, Domestic Labour and the Megamachine. Third Text, 29(4-5), 356-376.

DeVault, Marjorie L. 1991. Feeding the Family: The Social Organization of Caring as Gendered Work. Chicago, IL: University of Chicago Press.

Diner, H. A. (2001). Hungering for America. Italian, Irish, Jewish foodways in the age of migration. Cambridge, MA: Harward University Press.

Dubisch, J. (2014). Culture Enters Through the Kitchen: Women, food and social boundaries in rural Greece. Princeton University Press. New Haven, Connecticut.

Dywer, S., \& Buckle, J.L. (2009) The Space Between: On being an insider-outsider in qualitative research. International journal of qualitative methods. 8 (1), 54-63.

Eastham, A., MacKinnon, M., Reese, D., \& Monckton, S. (2002). The Excavations of San Giovanni di Ruoti, vol III. The Faunal and Plant Remains. Phoenix, 3-15. 
Ehlers, T. B. (1991). Debunking marianismo: Economic vulnerability and survival strategies among Guatemalan wives. Ethnology, 30(1), 1-16.

Girard, A., \& Sercia, P. (2013). Immigration and food insecurity: social and nutritional issues for recent immigrants in Montreal, Canada. International Journal of Migration, Health and Social Care, 9(1), 32-45.

Gordon, D. (2004). "I'm tired. You clean and cook." Shifting gender identities and second language socialization. TESOL Quarterly, 38(3), 437-457.

Holtzman, J. D. (2002). Food and memory. Annu. Rev. Anthropol., 35, 361-378.

Kanuha, V. K. (2000). "Being" native versus "going native": Conducting social work research as an insider. Social Work, 45(5), 439-447.

King, N., \& Horrocks, C. (2010). Interviews in qualitative research SAGE.

Koc, M., \& Welsh, J. (2001). Food, foodways and immigrant experience. Toronto: Centre for Studies in Food Security.

Levi-Strauss, C. (1966). The Culinary Triangle. Parisian Review 33: 586-595. 1969 The Raw and the Cooked.

Lloyd, S. A., Few, A. L., \& Allen, K. R. (Eds.). (2009). Handbook offeminist family studies. Sage.

Marano, M. R. (2004). Marianismo. In Encyclopedia of Women's Health (pp. 757-759). Springer University and Publishing.

Mendez-Luck, C. A., \& Anthony, K. P. (2015). Marianismo and Caregiving Role Beliefs Among US-Born and Immigrant Mexican Women. The Journals of Gerontology Series B: Psychological Sciences and Social Sciences.

Mishra, P. (2015). Colonialism and Its' Gastro-politics Re-visiting Gandhi's Vegetarianism.

Montanari, M. (2006). Food is culture. Columbia University Press.

Norris, D. (2013). Cultural Diversity May Be Increasing in Both Canada and the United States, but Important Differences Remain.

Pangborn, R. M., \& Bruhn, C. M. (1971). Concepts of food habits of 'other'ethnic groups. Journal of Nutrition Education, 2(3), 106-110.

Pollock, N. (2009). 6. Food and Transnationalism: Reassertions of Pacific Identity. Migration and Transnationalism: Pacific Perspectives, 103-114.

Richard G Parker, "Behaviour in Latin American Men: implications for HIV/AIDS interventions," International Journal of STD and AIDS 7, no 2. (1996): 62. 
Owen-Jones, O. (2007). Food choice, symbolism, and identity: Bread and butter issues for folkloristics and nutrition studies (American Folklore Society presidential address, October 2005). Journal of American Folklore, 120(476), 129-177.

Romo, R., \& Gil, J. M. (2012). Ethnic identity and dietary habits among Hispanic immigrants in Spain. British Food Journal, 114(2), 206-223.

SAEZ, PEDRO A. "Factors Influencing Masculinity Ideology among Latino Men." Journal of Men's Studies 17.2 (2009): 116-128.

Satia-Abouta, J., Patterson, R. E., Neuhouser, M. L., \& Elder, J. (2002). Dietary acculturation: applications to nutrition research and dietetics. Journal of the American Dietetic Association, 102(8), 1105-1118.

Stevens, E. P. (1973). Machismo and marianismo. Society, 10(6), 57-63.

Sutton, D. E. (2010). Food and the Senses. Annual Review of Anthropology, 39, 209-223.

Torres, Jos B. "The myth of sameness among Latino men and their machismo." American journal of orthopsychiatry 72.2 (2002): 163-181.

Trapido, A. (2011). The Struggle for Sunday Lunch: Gastropolitics in the Life of Nelson Mandela. Gastronomica, 11(1), 53-60.

Vallianatos, H., \& Raine, K. (2008). Consuming food and constructing identities among Arabic and South Asian immigrant women. Food, Culture \& Society, 11(3), 355-373.

Veronis, L. (2010). Immigrant participation in the transnational era: Latin Americans' experiences with collective organising in Toronto. Journal of International Migration and Integration/Revue de l'integration et de la migration internationale, 11(2), 173-192.

Veronis, L. (2006). The Canadian Hispanic Day Parade, or how Latin American immigrants practise (sub) urban citizenship in Toronto. Environment and Planning A, 38(9), 1653-1671.

Wandel, M., Råberg, M., Kumar, B., \& Holmboe-Ottesen, G. (2008). Changes in food habits after migration among South Asians settled in Oslo: the effect of demographic, socio-economic and integration factors. Appetite, 50(2), 376-385.

Watson, K. D. (1999). “The way I research is who I am”: The subjective experiences of qualitative researchers. Unpublished master's thesis, York University, Toronto, Ontario, Canada.

Weller, D., \& Turken, D. (2014). Contextualizing the Immigrant Experience: The Role of Food and Foodways in Identity Formation and Maintenance for First and Second Generation Latinos in Ithica, New York. Ecology of Food and Nutrition, 54 (1), 57-73. 
Wilkinson, L. (2013). Introduction: developing and testing a generalizable model of immigrant integration. Canadian Ethnic Studies, 45(3), 1-7.

Wong, L. L., \& Tézli, A. (2013). Measuring social, cultural, and civic integration in Canada: the creation of an index and some applications. Canadian Ethnic Studies, 45(3), 9-37. 